\title{
APPLICABILITY OF INLET AIR FOGGING TO MARINE GAS TURBINE
}

Zygfryd Domachowski

Marek Dzida

Gdańsk University of Technology, Poland

\begin{abstract}
The dependency of marine gas turbine on the ambient temperature leads to a decrease of the gas turbine power output in arid areas. Very often gas turbine power output demand is high and the power margins originally designed into the driver, has been exhausted. In such circumstances the inlet air fogging is an effective compensation of gas turbine power. In this paper an analysis of inlet air fogging applicability to marine gas turbine has been conducted. Different areas of ship's voyage have been taken into account. The use of inlet air fogging in marine gas turbine must be evaluated on the basis of turbine characteristics, climate profile of ship's voyage, and expectations of gas turbine power augmentation. The authors expect that the considerations provide useful guidance for users of marine gas turbines to decide the feasibility of installing an inlet air fogging system.
\end{abstract}

Keywords: marine gas turbine, inlet air fogging, applicability

\section{INTRODUCTION}

The marine gas turbine sector is listing of more than 41150 gas turbine installations, $3916(9,51 \%)$ of which are marine gas turbines used for propulsion. This assessment is based on the Forecast International Industrial and Marine Gas Turbine Database. The advantages of gas turbine for ships include the reliability, power density, and low noise. Unfortunately in hot and dry regions gas turbine power is dramatically reduced because of the reduction in gas turbine air mass flow. Temperature - power relationship for LM 500, LM 2500, LM 2500+, LM 6000 gas turbines has been illustrated in Fig.1.

Cooling the air to the wet-bulb temperature can boost the gas turbine power and efficiency. The inlet air fogging of marine gas turbine has been considered. In a stationary application of gas turbine (in the power application and mechanical drive) the selection of the climatic design point for the design of power augmentation system, has been suggested in the literature. This approach can be based on locally collected weather data. A detailed analysis of the evaporative cooling potential in terms of Equivalent Cooling Degree Hours (ECDH) is then carried out. The final decision as to the design point for the cooling system depends on the revenues to be generated by power augmentation and installation costs.

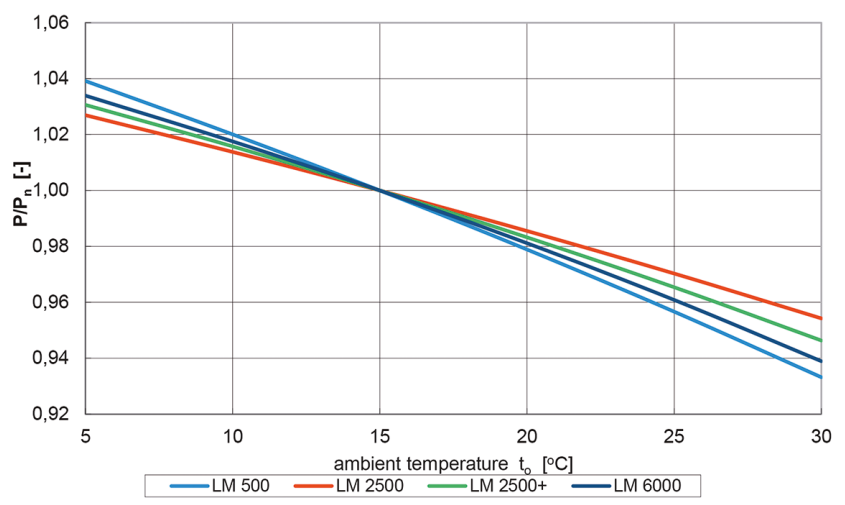

Fig. 1. Typical ambient temperature - power relation for marine gas turbines 
The marine gas turbines are advantageous to all fast ships such as cruise ships, fast ferries, fast cold storage ships, general refrigerated ships, fruit carriers, packet ships, mega - yachts, and naval ships. All of them need prime mover operation at maximum performance parameters. Full power operation at optimal parameters results in maximum speed of a ship on one hand and environmentally friendly conditions on the other hand. Above the air temperature design point the thermal efficiency of gas turbine falls, which results in power output decrease. Very often when the gas turbine power output decreases on hot days, the power output demand is high and the designed power margins have been exhausted. In such circumstances the augmenting of gas turbine power output can have an important impact on profitability. This paper is focussed on a climate analysis to determine the expected output power benefits.

Both short and long sea voyage of a ship has been taken into account. The Baltic Sea and the Mediterranean can be considered in case of short voyage of e.g. a gas turbinepropelled ferry. For a long sea voyage the distance between the Baltic Sea region and the Far East area has been assumed as an example. Air temperature data in January and July for some Baltic Sea and Mediterranean ports and on the route from the Baltic Sea to Far East area, have been collected. Having such database, any ship gas turbine operator is able to calculate the potential for evaporative cooling in a region of ship's location. The Equivalent Cooling Degree Hours multiplied by the gas turbine specific cooling number $\left(\mathrm{kW} /{ }^{\circ} \mathrm{C}\right)$ makes it possible to calculate the ( $\mathrm{kW}$ - hours) capacity available from using the evaporative fogging.

\section{AIR COOLING AS A WAY OF GAS TURBINE POWER AUGUMENTATION}

An ambient temperature increase provokes gas turbine output decrease which induces problem in the ship drive during high power demand. To reduce the dependence of gas turbine output on ambient temperature the power augmentation is needed. When the power output demand is high and the designed power margins have been exhausted an air cooling technology could be considered. There are two possible cooling technologies: an evaporative technology or chilling. In the ship use the evaporative cooling seems to prevail over the chilling. Weight of such installation and its size is smaller.

The evaporative cooling consists in latent heat water vaporization. The evaporating water cools the air at the gas turbine inlet. The effectiveness of evaporative cooler can be defined as follows :

$$
E=\frac{T_{1 D B}-T_{2 D B}}{T_{1 D B}-T_{2 W B}}
$$

where : $T_{1}$ denotes inlet temperature, $T_{2}$ - exit temperature of evaporative cooler, $D B$ - dry bulb, $W B$ - wet bulb, as presented by Meher - Homji et al. in [1,2].
The direct inlet air fogging is a method of air cooling where demineralized water is converted into a fog by means of special nozzles operating at $7 \div 14 \mathrm{MPa}$ pressure. This technique is applied on a large scale because of its low first cost and effectiveness attaining near $100 \%$. The relative humidity at the gas turbine inlet will be $100 \%$ which gives the lowest temperature possible at the wet bulb temperature.

In a given location it is possible to provide an estimation of the cooling potential if only there are sufficient weather data. The Equivalent Cooling Degree Hours (ECDH) calculations is an useful measure when inlet air fogging is applied. The $\mathrm{ECDH}$ is a number $\left({ }^{\circ} \mathrm{C}\right.$ - hours $)$ that defines the total amount of cooling that can be derived in a given time period. The $\mathrm{ECDH}$ is calculated with a lower limit of Minimum Wet Bulb Temperature (MWBT) varying between $7,2^{\circ} \mathrm{C}\left(45^{\circ} \mathrm{F}\right)$ and $12^{\circ} \mathrm{C}$ $\left(55^{\circ} \mathrm{F}\right)$, see $[3,4]$. The MWBT is selected in order to avoid the possibility of inlet icing. The ECDH is calculated as the difference between the coincident dry bulb temperature and the wet bulb temperature, multiplied by the number of hours during which this difference exists if the wet bulb temperature is above the MWBT lower limit. At a given location the ECDH number would be multiplied by the gas turbine specific cooling number $\left(\mathrm{kW} /{ }^{\circ} \mathrm{C}\right)$ to compute a ( $\mathrm{kW}$ - hours) capacity available from using the inlet air fogging.

Considering the role of inlet air cooling in marine gas turbine, we take into account a short and long sea voyage of a ship, separately.

\section{THE ROLE OF MARINE GAS TURBINE INLET AIR FOGGING IN A SHORT SEA VOYAGE}

The possible role of marine gas turbine inlet air cooling depends on a region of ship's short voyage, e.g. of a gas turbine ferry. The difference can be observed by comparing the case of the Baltic Sea voyage with the Mediterranean one. In Fig. 2 there is presented the average air temperature on the Baltic Sea coast in winter (January), and summer (July). Similar data are illustrated in Fig. 3 for the Mediterranean.

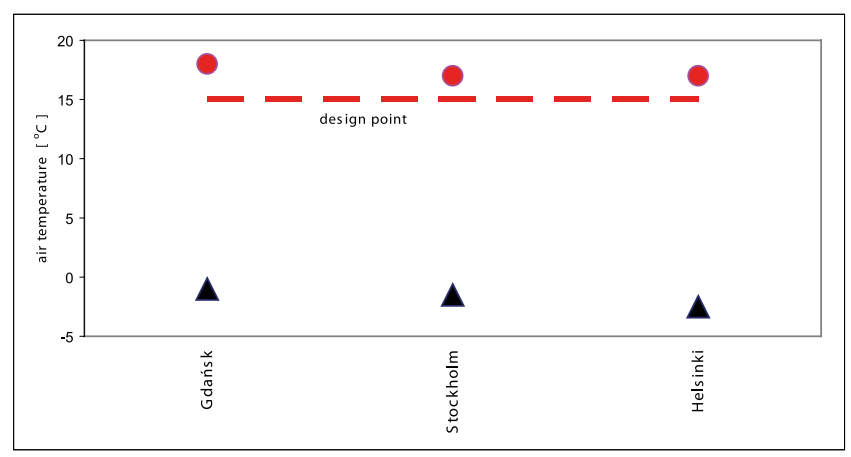

Fig. 2. Average air temperature on the Baltic Sea coast in January (A), and July (O)

The value of the Average Equivalent Cooling Degree Hours calculated for the Baltic Sea area have been below 6000 (degree-hours) a year and between 12000 and 25000 (degree-hours) for the Mediterranean area, as presented in [5]. Therefore an inlet air fogging implementation would 


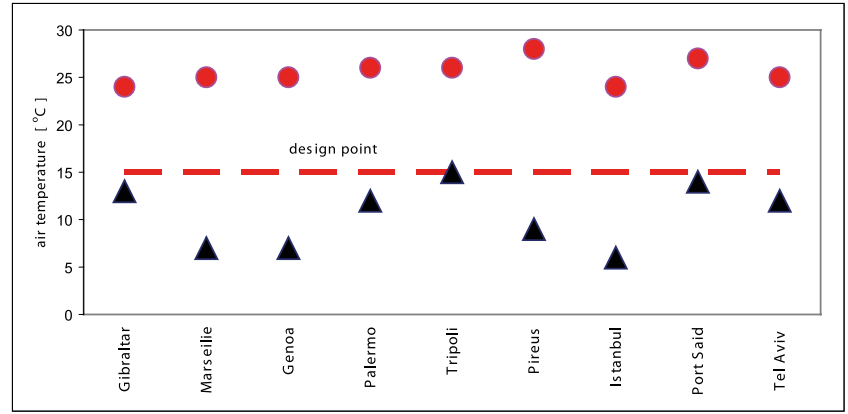

Fig. 3. Average air temperature on the Mediterranean coast

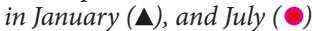

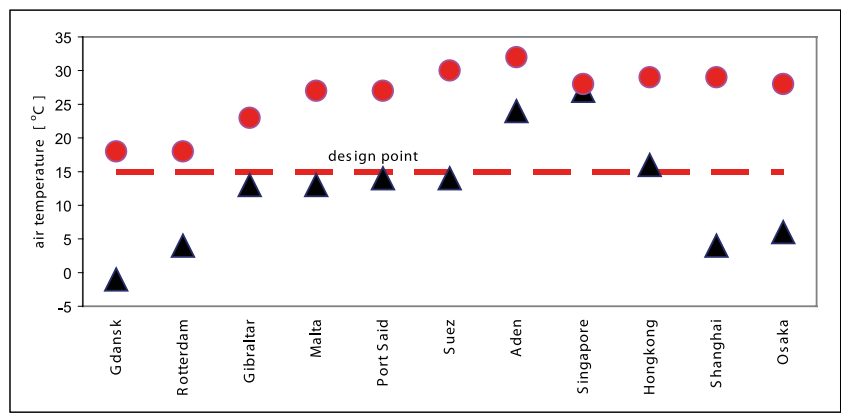

Fig. 4. Average air temperature on the route from the Baltic Sea to Far East area in January ( $\mathbf{\Delta})$, and July $(\mathbf{O})$ presumably not be profitable for the navigation limited to the Baltic Sea area. It could probably be profitable for the navigation within the Mediterranean area. A lower ECDH value may not eliminate consideration on the use of inlet air fogging since the number of operating hours would also be a deciding factor.

The use of inlet air fogging in marine gas turbine must be evaluated on the basis of turbine characteristics, climate profile of ship's voyage, and expected amount of gas turbine power augmentation.

\section{MARINE GAS TURBINE INLET AIR FOGGING DURING A LONG SEA VOYAGE IN HOT REGION}

The average air temperature in several ports along the route of sea voyage between the Baltic Sea region and the Far East area is presented in Fig 4. acc.[5].

Tab. 1 contains monthly and yearly ECDH values available during the voyage from the Baltic Sea to the Far East area. It can be seen that yearly available ECDH value calculated for a voyage from the Baltic Sea region to the Far East area have been between 6000 and 37000 (degree-hours).

According to [6] the rating power of e.g. LM 2500 gas turbine is equal to $22375 \mathrm{~kW}$. Therefore its specific cooling number is $68,6 \mathrm{~kW} /{ }^{\circ} \mathrm{C}$, approximately. In a voyage from the Baltic Sea to the Far East area such gas turbine can gain energy between $411690 \mathrm{kWh}$ and $2536755 \mathrm{kWh}$.

Tab. 1. Monthly and yearly ECDH values available during the voyage from the Baltic Sea to the Far East area, [kWh]

\begin{tabular}{|c|c|c|c|c|c|c|c|c|c|c|c|c|c|}
\hline & Jan. & Feb. & Mar. & Apr. & May & Jun. & Jul. & Aug. & Sep. & Oct. & Nov. & Dec. & Yearly \\
\hline \multicolumn{14}{|c|}{ Voyage from the Baltic Sea to the Far East area } \\
\hline Stockholm & 0 & 0 & 0 & 22 & 394 & 1189 & 2269 & 1786 & 200 & 10 & 0 & 0 & 5871 \\
\hline Oslo & 0 & 0 & 0 & 11 & 333 & 1300 & 2482 & 2035 & 165 & 1 & 0 & 0 & 6328 \\
\hline Amsterdam & 0 & 0 & 4 & 93 & 686 & 1110 & 1565 & 1675 & 759 & 201 & 9 & 0 & 6104 \\
\hline Lisbon & 110 & 151 & 549 & 992 & 1855 & 2744 & 3542 & 3543 & 2990 & 1745 & 661 & 244 & 19127 \\
\hline Tripoli & 244 & 620 & 1710 & 3030 & 4602 & 4993 & 5087 & 4954 & 4274 & 3582 & 2103 & 786 & 35984 \\
\hline Alexandria & 602 & 730 & 1336 & 2609 & 3061 & 3043 & 2916 & 3122 & 3266 & 3051 & 2412 & 1313 & 27462 \\
\hline Madras & 2485 & 2497 & 3030 & 3066 & 4177 & 4704 & 3928 & 3645 & 2899 & 2279 & 1937 & 2276 & 36921 \\
\hline Singapore & 1595 & 1498 & 1708 & 1402 & 1439 & 1485 & 1546 & 1632 & 1377 & 1428 & 1040 & 1162 & 17313 \\
\hline Manila & 2462 & 2567 & 3251 & 3378 & 3096 & 2295 & 2008 & 1860 & 1729 & 1908 & 2063 & 2219 & 28836 \\
\hline Hong Kong & 1529 & 1299 & 1531 & 1735 & 1945 & 2106 & 2406 & 2447 & 2736 & 3300 & 3004 & 2184 & 26221 \\
\hline Shanghai & 2 & 47 & 109 & 894 & 1991 & 1669 & 1889 & 1938 & 1911 & 1804 & 587 & 54 & 12894 \\
\hline Pusan & 0 & 8 & 8 & 585 & 2025 & 1815 & 1507 & 2041 & 2265 & 1922 & 307 & 10 & 12494 \\
\hline Osaka & 0 & 7 & 38 & 999 & 2681 & 2817 & 2897 & 3389 & 2811 & 2082 & 533 & 16 & 18271 \\
\hline
\end{tabular}




\section{ROLE OF AMBIENT TEMPERATURE DESIGN POINT FOR MARINE GAS TURBINE IN HOT AREA}

Let's assume a gas turbine which drives a ship sailing between the Mediterranean Area and the Far East Area. In such ship's voyage the average ambient temperature exceeds $15^{\circ} \mathrm{C}$ during the most part of a year, see Fig.4. The relation ambient temperature - marine gas turbine power, presented in Fig. 1, corresponds to the ambient temperature design point equal to $15^{\circ} \mathrm{C}$. A similar relation for a gas turbine in which ambient temperature design point has been assumed to be $20^{\circ} \mathrm{C}$, is shown in Fig. 5 .

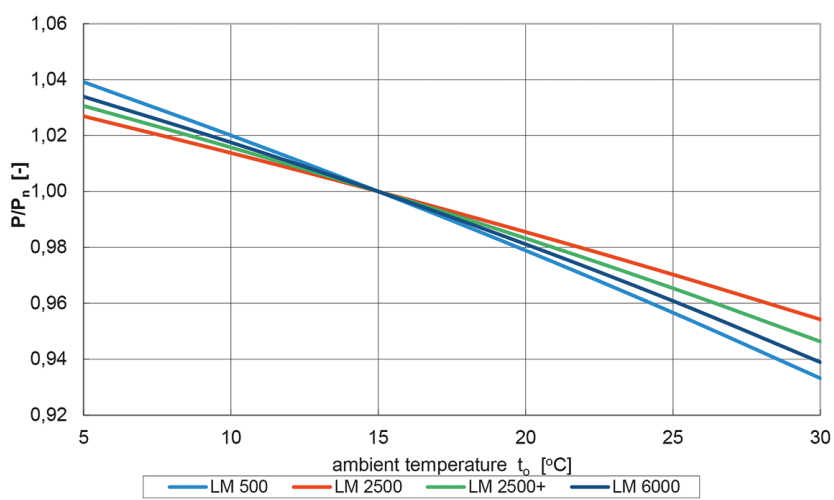

Fig. 5. Relation between ambient temperature and gas turbine power for the Ambient Temperature Design Point of $20^{\circ} \mathrm{C}$

It is evident that the selection of ambient temperature design point impacts the available power of gas turbine in a hot area. An example relation for LM2500 marine gas turbine is given in Fig. 6.

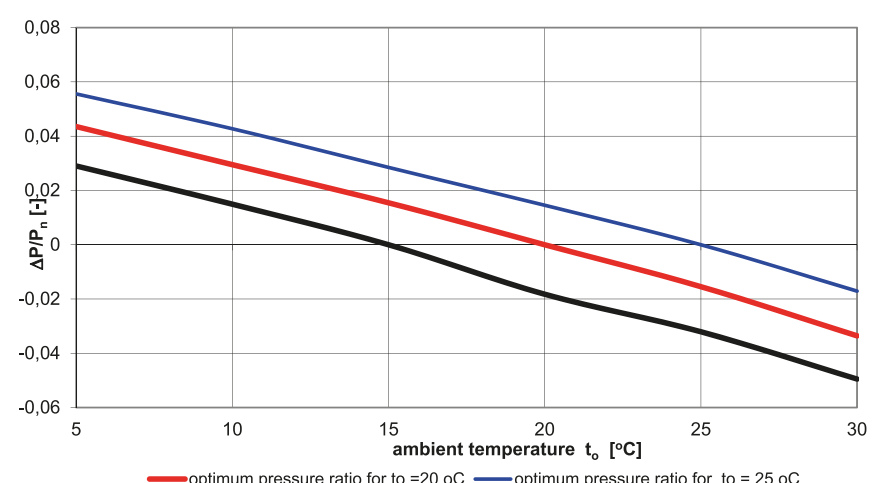

Fig. 6. Example relation between ambient temperature and gas turbine power for different values of Ambient Temperature Design Point

In the same time, for an inlet air system, the selection of the ambient temperature design point will impact the hardware sizing. The design of high pressure pumps and nozzle arrays depends on water flow. On one hand, to implement an inlet air fogging into a marine gas turbine, very little modification of the inlet air system is needed. On the other hand, a detailed technical and economical analysis should be carried out to properly determine size the fogging system. An over-designed fogging system may reduce the economic effectiveness of the system while an under-designed one may lead to a lower power boost than expected.

\section{SUMMARY}

The presented investigation has been conducted to examine the applicability of inlet air fogging to marine gas turbine. Different areas of ship's voyage have been taken into account. To apply an inlet air fogging to marine gas turbine several factors should be considered. Among them, the most important are climate profile of ship's voyage, cost of the fogging system to be installed, amount of (MW - hours) boost gained by means of inlet air fogging (i.e. benefit to be attained as a result of it). If an inlet air fogging system is feasible the system should be adjusted to the achievable cooling to avoid its over-sizing or under-sizing.

This work has been completed with the analysis of average ambient temperatures for key ports along the route of both a short and long voyage. This has been done by using the ECDH data along with the cooling design points for a popular marine gas turbine - the LM2500.

This paper was aimed at providing the background analysis for future research.

\section{REFERENCES}

1. Meher - Homji, C. B., Mee, T. R.: Gas Turbine Power Augmentation by Fogging of Inlet Air. Proceedings of the 28th Turbomachinery Symposium, Turbomachinery Laboratory, Texas A\&M University, September 1999, Houston, USA.

2. Meher-Homji, C. B., Mee, T. R.: Intel Fogging of Gas Turbine Engines, part B: Practical Considerations, Control and O\&M Aspects. Proceedings of ASME Turbo Expo 2000, May 8-11, 2000, Munich, Germany, ASME Paper 2000 - GT-308.

3. Chaker, M.A., Meher - Homji, C. B.: Inlet Fogging of Gas Turbine Engines: Climatic Analysis of Gas Turbine Evaporative Cooling Potential of International Locations. Proceedings of ASME Turbo Expo 2002, June 3-6, 2002, Amsterdam, The Netherlands, ASME Paper 2002 - GT - 30559.

4. Chaker, M.A., Meher - Homji, C. B.: Selection of Climatic Design Points for Gas Turbine Power Augmentation. Proceedings of ASME Turbo Expo 2011, June 6-10, 2011, Vancouver, British Columbia, Canada, ASME Paper GT2011-46463.

5. Domachowski, Z., Dzida, M.; Air Fogging of Marine Gas Turbine in Power Output Loss Compensation. Polish Maritime Research No 4, Vol. 22, 2015, pp. 53-58.

6. Marine Drive Specifications, Handbook 1999/2000, Turbomachinery, Vol. 40, No 6, p.124. 


\title{
CONTACT WITH THE AUTHORS
}

Zygfryd Domachowski

e-mail:omachow@pg.edu.pl

Gdańsk University of Technology Narutowicza 11/12, 80-233 Gdansk

Poland

\author{
Marek Dzida \\ e-mail:dzida@pg.edu.pl
}

Gdańsk University of Technology

Narutowicza 11/12, 80-233 Gdansk

Poland 